\title{
Pelatihan Manajemen untuk Peningkatan Kualitas Pengelolaan Taman Pendidikan Al-Quran
}

\author{
Adim Firmansyah ${ }^{1)}$, Aripriharta Aripriharta ${ }^{2)}$, Ahmad Munjin Nasih ${ }^{3)}$, Ahmad Taufiq ${ }^{4)}$, \\ Nandang Mufti' ${ }^{5)}$, Satia Nur Maharani' \\ 1,2) Jurusan Teknik Elektro, Universitas Negeri Malang, Jawa Timur, Indonesia \\ 3) Jurusan Sastra Arab, Universitas Negeri Malang, Jawa Timur, Indonesia \\ ${ }^{4,5)}$ Jurusan Fisika, Universitas Negeri Malang, Jawa Timur, Indonesia \\ 6) Jurusan Akuntansi, Universitas Negeri Malang, Jawa Timur, Indonesia \\ Email: *adimfirmansyah@gmail.com¹; aripriharta.ft@um.ac.id²; munjin.nasih.fs@um.ac.id³ \\ ahmad.taufig.fmipa@um.ac.id ; nandang.mufti.fmipa@um.ac.id ${ }^{5}$; $\underline{\text { satia.nur.fe@um.ac.id }}$
}

Cara Mensitasi Artikel ini:

Firmansyah A., Aripriharta, A., Nasih, A. M., Taufiq A., Mufti, N., \& Maharani, S. N. (2021). Pelatihan manajemen untuk peningkatan kualitas pengelolaan Taman Pendidikan Al-Quran. ABDIMASY: Jurnal Pengabdian dan Pemberdayaan Masyarakat, 2(2), 53-59. https://doi.org/10.46963/ams.v2i2.461

\section{DOI}

https://doi.org/10.46963/ams.v2i2.416

\section{Sejarah Artikel}

$\begin{array}{ll}\text { Diterima } & : 08 / 11 / 2021 \\ \text { Direvisi } & : 22 / 12 / 2021 \\ \text { Diterbitkan } & : 31 / 12 / 2021\end{array}$

\section{*) Corresponding Author}

adimfirmasyah@gmail.com

\section{Editorial Address}

Kampus Panam (Parit Enam) STAI Auliaurrasyidin, Jl. Gerilya No. 12 Tembilahan Barat, Riau, Indonesia, 29213

Kata Kunci:

Kualitas; manajemen TPQ; pelatihan; $T P Q$

Keywords:

Quality; $T P Q$ management; training; $T P Q$
Abstract: Al-Quran Education Park (TPQ) is one of the places to learn that is spread in almost all parts of Indonesia. Especially for Malang and surrounding areas, the management of TPQ is still not optimal, for example TPQ in Mojosari Village, Gambiran, Kepanjen District, Malang Regency. Management that has not reached the good category needs a helping hand from the UM abdimas team, considering the UM RENSTRA which wants to realize the downstreaming of science and research results. The Abdimas team consisting of lecturers across faculties, apart from having experience in research and service, also has a real role in their respective regions regarding TPQ and takmir. The undoubted competence of the team and the additional composition of students are expected to assist the implementation of management training activities at partner $T P Q$. Management training is expected to improve the quality of TPQ management from several aspects, namely: finance, programs, and governance. This activity is carried out using training methods (knowledge and skills) which are carried out in a structured and periodic manner. Each activity evaluates (measures) the achievement/success of the Abdimas program. Questionnaires are provided as data collectors for final analysis. In general, activities have been running smoothly and the public is quite satisfied with the index reaching 0.75 .

Abstrak: Taman Pendidikan Al Quran (TPQ) merupakan salah satu tempat belajar yang tersebar hampir di seluruh wilayah Indonesia. Khusus daerah Malang dan sekitarnya, pengelolaan $T P Q$ masih belum optimal, contohnya $T P Q$ di Desa Mojosari, Gambiran Kecamatan Kepanjen, Kabupaten Malang. Pengelolaan yang belum mencapai kategori baik ini perlu uluran tangan tim abdimas UM, mengingat RENSTRA UM yang ingin mewujudkan hilirisasi keilmuan dan hasil penelitian. Tim Abdimas yang terdiri dari dosen lintas Fakultas ini, selain memiliki pengalaman dalam penelitian dan pengabdian juga memiliki peran nyata di daerahnya 

mahasiswa diharapkan dapat membantu pelaksanaan kegiatan pelatihan manajemen di TPQ mitra. Pelatihan manajemen diharapkan dapat meningkatkan kualitas pengelolaan TPQ dari beberapa aspek, yaitu: keuangan, program, dan tata kelola. Kegiatan ini dilaksanakan dengan metode pelatihan (knowledge dan skill) yang dilakukan secara terstruktur dan berkala. Pada setiap kegiatan dilakukan evaluasi (pengukuran) ketercapaian/ kesuksesan program Abdimas ini. Angket disediakan sebagai data collector untuk analisis akhir. Secara umum, kegiatan telah berlangsung lancar dan masyarakat cukup puas dengan indeks mencapai 0,75 .

\section{PENDAHULUAN}

Menurut PP No. 5 tahun 2007, Pendidikan Al-Quran bertujuan meningkatkan kemampuan peserta didik membaca, menulis, memahami, dan mengamalkan kandungan Al-Quran. Pendidikan Al-Quran terdiri TKQ (Taman Kanak-Kanak), TPQ (Taman Pendidikan Al-Quran), TQA (Taman Qur'an lil Aulad), dan bentuk lain yang sejenis. Kurikulum pada Pendidikan AlQuran yaitu membaca, menulis, dan menghafal ayat-ayat Al-Quran, tajwid, dan menghafal doa-doa syarat (Kemenag, n.d.-a).

Berdasarkan data dari Pengurus Cabang Nadhatul Ulama di Kabupaten Malang pada tahun 2017 tercatat ada 475 ponpes (pondok pesantren), 4.251 TPQ, dan 2.046 madin. TPQ dan madin adalah tempat kita untuk membentuk karakter nasionalisme dan kebangsaan (Malang, n.d.).

Menurut Kementerian Agama, jumlah TPQ yang saat ini terdaftar oleh kementerian agama yaitu 148.054 lembaga, untuk jumlah santri secara keseluruhan yaitu 7.418 .728 orang, dan untuk tenaga pengajar yaitu 596.520 orang (Kemenag, n.d.-b). Hal ini merupakan salah satu penyebab yang mengakibatkan turunnya tingkat kualitas manajemen dari lembaga TPQ yang ada di Malang, salah satunya TPQ Nurul Hidayah. Untuk dapat membangun kualitas manajemen TPQ diperlukan beberapa metode yang dapat diterapkan pada TPQ Nurul Hidayah. Kegiatan PKM ini merupakan upaya dari TIM PENGABDIAN PUI CAMRY Universitas Negeri Malang untuk membantu masyarakat daerah Mojosari di kabupaten Malang, khususnya TPQ (Taman Pendidikan Al-Quran) dalam hal kualitas manajemen (Burde et al., 2015; Permani, 2011).

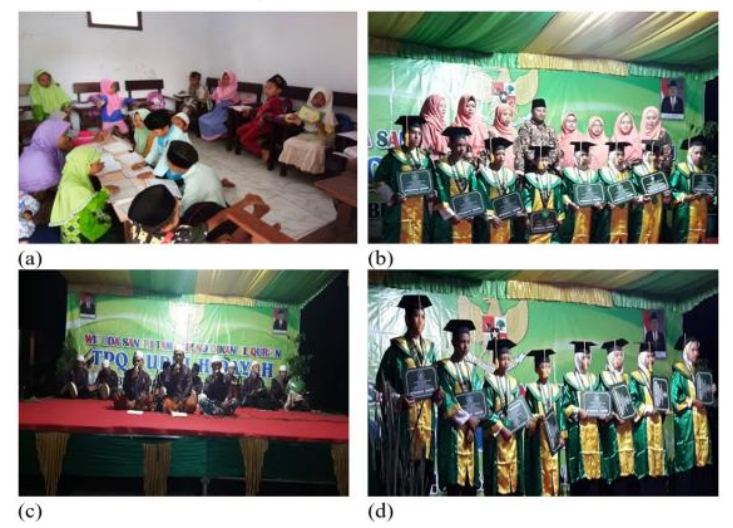

Gambar 1. (a) Kegiatan Belajar

Mengajar, (b) Foto Bersama Tenaga

Pengajar dan Wisudawan Santri, (c) 
Kegiatan Khataman Wisudawan Santri, (d) Foto Wisudawan Santri

Berdasarkan hasil wawancara dengan pihak pengelola TPQ Nurul Hidayah, terdapat beberapa poin permasalahan yang dihadapi oleh mitra yaitu: Kurang efektifnya proses belajar mengajar, Rasio tenaga pengajar dan jumlah santri, dan Perlunya manajemen yang lebih profesional, contoh yang paling sederhana adalah membentuk program bulanan, mingguan, dan harian, evaluasi/ ujian dan pembagian rapor.

\section{Solusi Dan Target}

Setelah

mempertimbangkan permasalahan mitra yang menginginkan kualitas manajemen TPQ, maka tim mengusulkan beberapa metode yang dapat diterapkan pada TPQ Nurul Hidayah. Metode yang disarankan yaitu dengan memperbaiki manajemen mulai dari hal-hal sederhana, yaitu: membuat beberapa program bulanan, harian, mingguan, hingga tahunan, serta mengadakan evaluasi ujian dan pembagian rapor, termasuk manajemen keuangan dan pengelolaan aset. Target sasaran kegiatan pengabdian ini adalah untuk meningkatkan kualitas manajemen TPQ Desa Mojosari, Gambiran Kecamatan Kepanjen, Kabupaten Malang.

\section{METODE}

Metode kegiatan ini didekati dengan menggunakan metode survei dan penyuluhan agar lebih efektif dan efisien dalam mencapai target luaran.

Observasi. Observasi ini bertujuan untuk menganalisis kebutuhan berdasarkan situasi pada lokasi pengabdian. Tim langsung berkunjung ke lokasi, melakukan pengecekan dan dokumentasi serta wawancara eksklusif dengan mitra. Tujuan observasi ini adalah untuk mengidentifikasi permasalahan.

Perencanaan manajemen TPQ. Membangun manajemen TPQ dari segala bidang, dimulai dari Manajemen dalam Bidang Pengelola, Manajemen dalam Bidang Administrasi, Manajemen dalam Bidang Kegiatan Belajar Mengajar, serta Manajemen dalam Bidang Keuangan seperti Gambar 2.

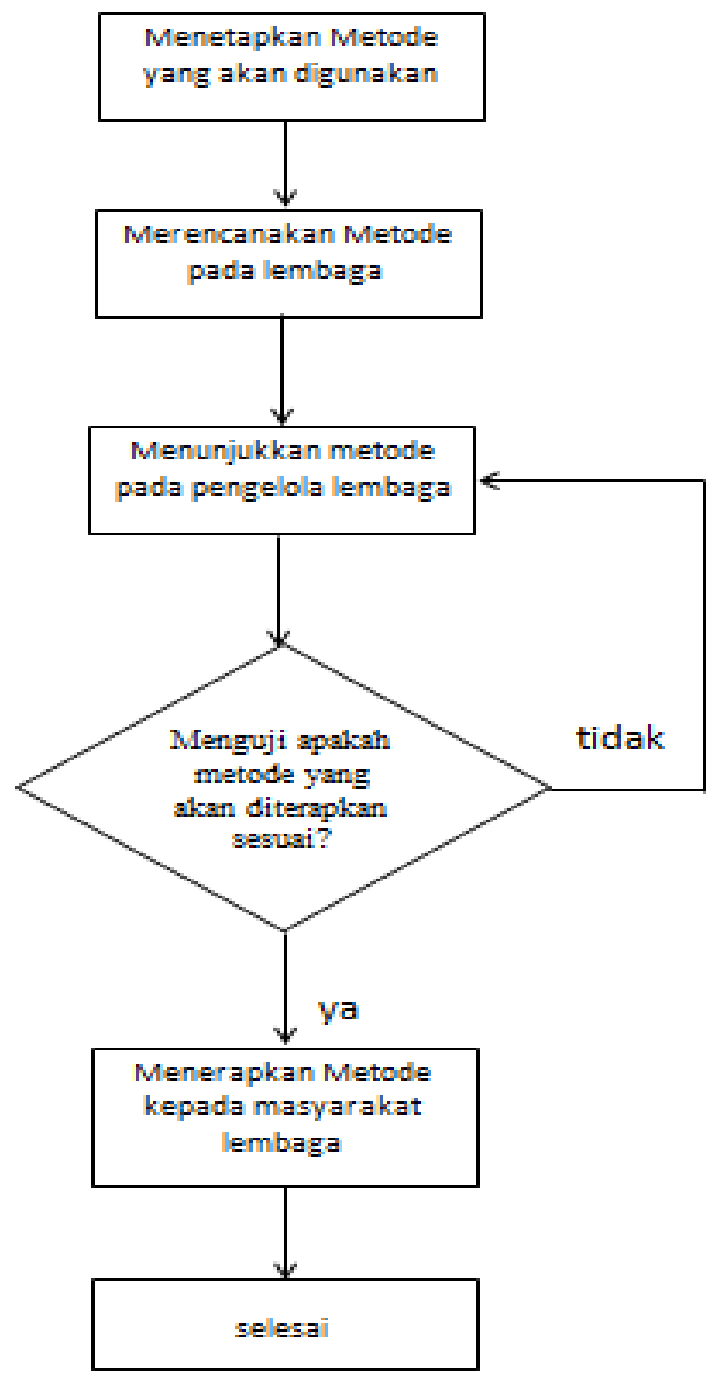

Gambar 2. Prosedur Perencanaan Metode Manajemen 
Pelatihan manajemen untuk peningkatan kualitas pengelolaan Taman Pendidikan Al-Quran

Manajemen dalam Bidang Pengelola. Dalam mendirikan sebuah lembaga, manajemen dalam bidang pengelola sangat diperlukan agar visi dan misi dari sebuah lembaga dapat mencapai target. Manajemen dalam bidang ini yaitu dengan mendeskripsikan tugas dan tanggung jawab dari masing-masing personel (Burde et al., 2015; Jonathan M.B. Stern, 2016; Permani, 2011).

\section{Manajemen dalam Bidang} Administrasi. Terdapat dua hal yang harus diperhatikan saat mendirikan sebuah lembaga, yaitu administrasi secara eksternal dengan lembaga yang terkait, dan administrasi internal kelembagaan yang terkait. Contoh dari administrasi eksternal yaitu lembaga sudah terdaftar di kementerian agama, sedangkan administrasi internal seperti administrasi pengumpulan dana.

Manajemen dalam Bidang Kegiatan Belajar Mengajar. Dalam kegiatan belajar mengajar, terdapat beberapa hal yang harus di perhatikan yaitu pembagian kelas santri, kurikulum pengajaran, rasio tenaga pengajar dengan santri, serta pelaksanaan ujian dan penerimaan raport.

Manajemen dalam Bidang

Keuangan. Dalam bidang ini peran bendahara sangat diperlukan guna untuk memikirkan manajemen pemasukan lembaga TPQ sehingga dapat memudahkan pengurus melakukan perencanaan kegiatan TPQ.

Pengujian metode. Metode yang telah di rancang akan dilakukan pengujian yaitu dengan diterapkan pada TPQ Nurul Hidayah. TPQ akan menerapkan proses manajemen dari awal, yaitu manajemen dalam bidang pengelola hingga manajemen dalam bidang keuangan.

Pelatihan metode. Setiap tenaga pengajar dari TPQ Nurul Hidayah akan dibimbing oleh tim untuk dapat menerapkan metode yang akan digunakan pada saat proses kegiatan belajar mengajar. Mekanisme pelatihan seperti Gambar 5 dilakukan langsung diruang belajar dengan praktik langsung setelah dibekali konsep melalui ceramah di kelas (Burde et al., 2015; Indrawati, 2014; Jamelaa Bibi Abdullah Jainabee Md Kassim, 2011) seperti Gambar 3.
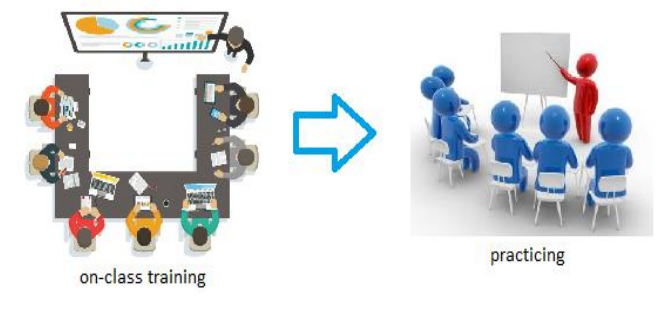

Gambar 3. Pelatihan

Dokumentasi dan Pelaporan. Dokumentasi proses kegiatan dari awal sampai akhir dilakukan menggunakan kamera/video secara mandiri dan menggunakan jasa profesional. Sedangkan laporan akhir dibuat sesuai format standar pengabdian masyarakat untuk diserahkan pada LPM Universitas Negeri Malang.

Publikasi. Diupayakan semaksimal mungkin untuk publikasi pada seminar/jurnal nasional/ Internasional, HKI, dan artikel dalam media online/cetak.

\section{HASIL DAN PEMBAHASAN}

Pelaksaan kegiatan pengabdian di TPQ mitra berlangsung dengan lancar sambil tetap menerapkan protokol covid19. Rangkaian acara kegiatan dimulai dari survei ke lokasi yang disambut oleh 
pimpinan mitra beserta beberapa ustazah pengajar TPQ. Survei ke lokasi TPQ dilakukan pada hari yang sama, dan disepakati bersama bahwa selain keperluan manajemen kebutuhan sarpras juga cukup urgen. Tim pengabdian Universitas Negeri Malang menghibahkan papan tulis, alat tulis, stand baca dan sound system dan gerai untuk memfasilitasi TPQ Desa Mojosari, Gambiran Kecamatan Kepanjen, Kabupaten Malang, Jawa Timur. Selain itu, tim UM juga menghibahkan perlengkapan kesehatan seperti masker dan faceshield kepada pengajar dan siswa TPQ mitra.

TPQ Nurul Hidayah berlokasi di kabupaten Malang yang berjarak $17 \mathrm{~km}$ dari Universitas Negeri Malang (Gambar 4). Perjalanan dari Universitas Negeri Malang menuju lokasi mitra dapat ditempuh sekitar 31 menit menggunakan kendaraan bermotor, tergantung kepadatan lalu lintasnya.

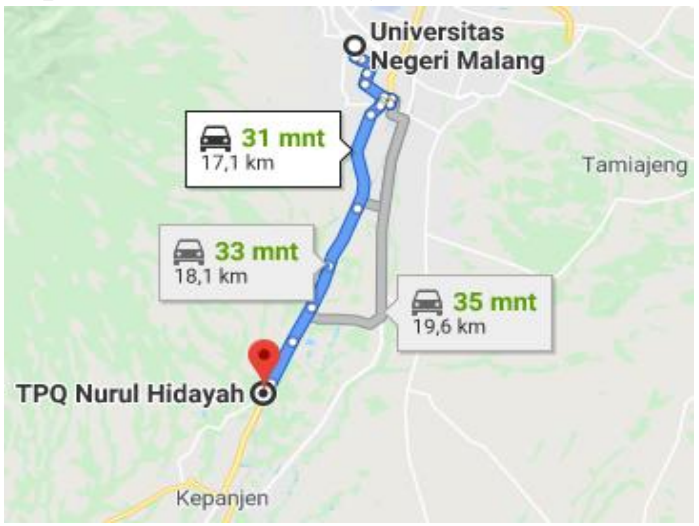

Gambar 4. Peta Lokasi Pengabdian TPQ Nurul Hidayah

Gambar 5 dan Gambar 6 memperlihatkan suasana sambutan mitra saat tim melakukan survei lapangan. Variabel kendala yang sangat luas dan beragam mulai dari latar belakang ekonomi orang tua, pengaruh lingkungan dan mindset yang modern menyebabkan solusi mengerucut pada pemanfaatan program aplikasi dan pemberian hibah sarpras.

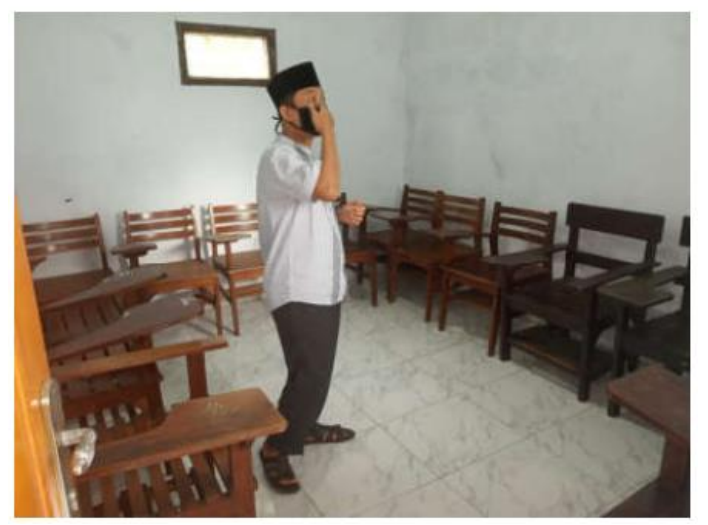

Gambar 5. Survei lapangan

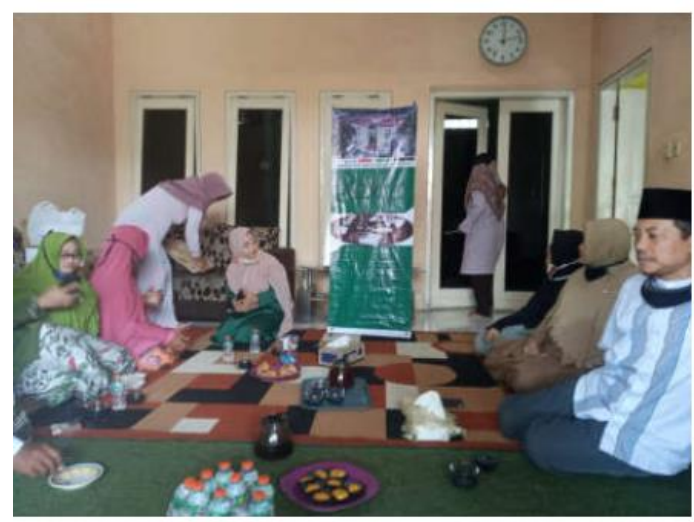

Gambar 6. Diskusi tata kelola (manajemen TPQ)

Model manajemen sederhana (Gambar 7) yang mengadopsi sistem pengelolaan sekolah, dimana terdiri dari kepala/ketua sebagai manajer dan sistem (pengajar dan manajemen), ortu sebagai pengawas serta peserta didik (santri). Model ini dilengkapi dengan komunikasi kekeluargaan dan dakwah bagi orang tua, di mana orang tua juga berhak mengawasi pembelajaran dari hasil/raport santri. Sistem manajemen juga menyangkut aspek pengelolaan aset dan keuangan (SPP/donasi). Perbaruan fitur yang dimiliki adalah Sistem evaluasi 
Pelatihan manajemen untuk peningkatan kualitas pengelolaan Taman Pendidikan Al-Quran

dengan rapor.ini memungkinkan orang tua untuk lebih peduli dan ikut mengawasi perkembangan anak-anaknya dalam mengaji, Sistem keuangan yang lebih modern dengan melibatkan donatur dari luar dan adanya sistem pembagian tugas yang jelas.

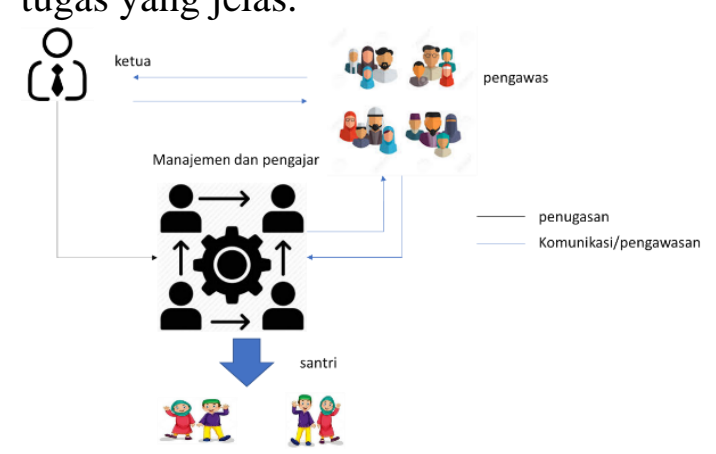

Gambar 7. Model MTPQ

Penerapan (implementasi) manajemen TPQ diringkas dengan memperkenalkan aplikasi android bernama MTPQ yang dikembangkan oleh tim UM. Berikut ini narasi spesifik produk Apps MPTQ. Gambar 6 dan Gambar 7 memperlihatkan antarmuka apps MTPQ yang sengaja dibuat sederhana agar mudah dipakai oleh pengajar yang rata-rata tidak terbiasa dengan smartphone.
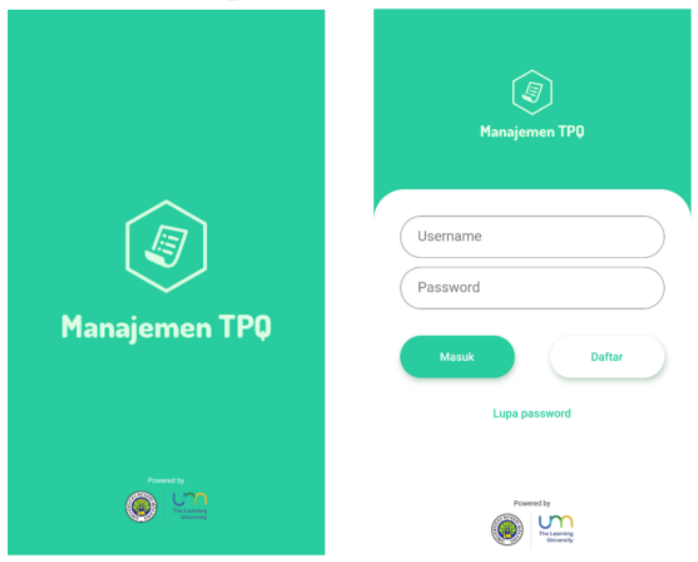

Gambar 8. Tampilan apps MTPQ (kiri: depan, kanan:login)

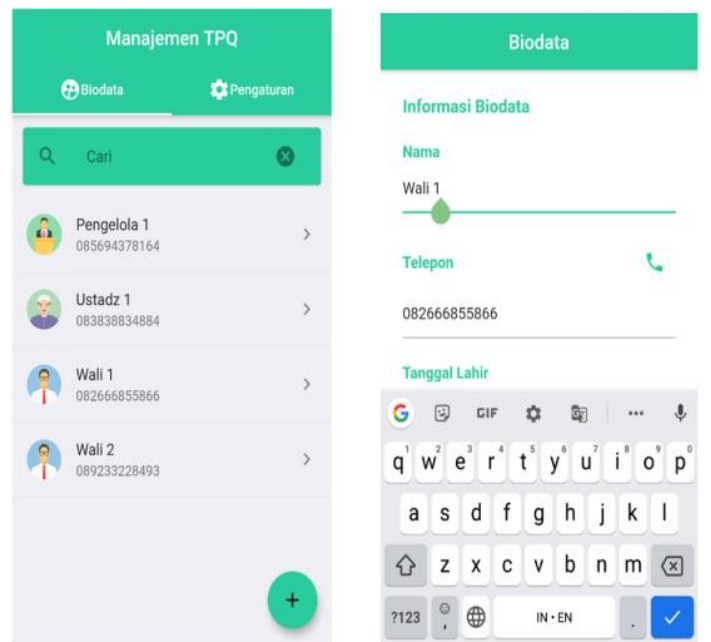

Gambar 9. Sebagian isi Apps MTPQ

(kiri: database, kanan:pencarian)

Kegiatan abdimas ini diharapkan menghasilkan 4 luaran berupa: 1 artikel pada jurnal nasional pengabdian masyarakat, 1 Hak cipta Apps, sebuah artikel dimuat dalam media cetak/online, dan sebuah video dokumenter diupload di channel Youtube. Kegiatan ini berdampak pada dua aspek, yaitu: tata kelola manajemen TPQ dan sarpras TPQ. Tata kelola TPQ menjadi lebih baik dengan adanya kegiatan ini. Antusiasme masyarakat mitra tampak jelas saat prosesi serah terima prasasti dan sarpras pun saat pelatihan apps MTPQ (Gambar $10)$.

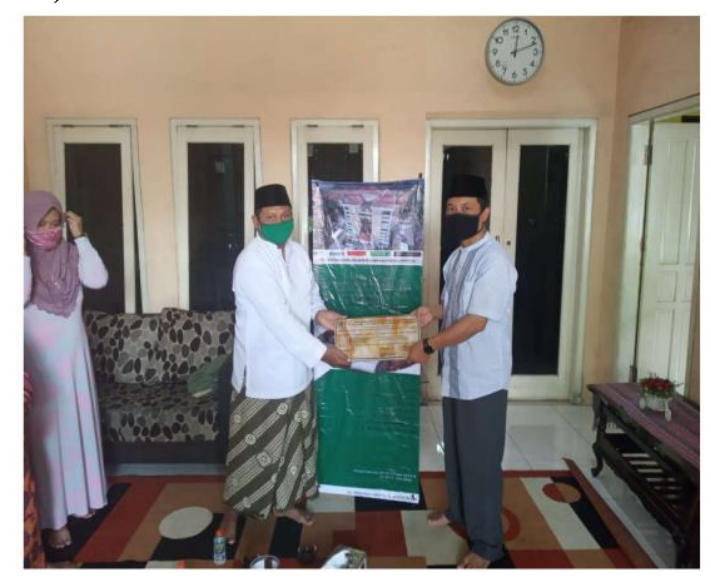

Gambar 10. Prosesi serah terima

Abdimasy: Jurnal Pengabdian dan Pemberdayaan Masyarakat 


\section{SIMPULAN}

Kegiatan pengabdian ini telah berlangsung dengan baik. Tata kelola TPQ menjadi lebih baik dengan adanya kegiatan ini. TPQ mitra mengalami peningkatan dalam hal manajemen dan sarpras. Indeks kepuasannya mencapai $0,75 \%$.

\section{DAFTAR PUSTAKA}

Burde, D., Middleton, J. A., \& Wahl, R. (2015). Islamic studies as early childhood education in countries affected by conflict: The role of mosque schools in remote Afghan villages. International Journal of Educational Development, 41, 7079.

Indrawati, N. K. (2014). Management by Inspiration: Implementation of Transformational Leadership on Business at Pondok Pesantren*) Sunan Drajat. Procedia - Social and Behavioral Sciences, 115, 79-90.

Jamelaa Bibi Abdullah Jainabee Md Kassim. (2011). Instructional leadership and attitude towards organizational change among secondary schools principal in Pahang, Malaysia. Procedia - Social and Behavioral Sciences, 15, 33043309.

Jonathan M.B. Stern, T. M. S. (2016). Private secondary schools in Indonesia: What is driving the demand? International Journal of Educational Development, 46, 111.

Kemenag. (n.d.-a). No Titles. https://kemenag.go.id/file/dokumen/ PP5507.pdf

Kemenag. (n.d.-b). No Titles. http://pendis.kemenag.go.id/file/dok umen/bukusaku1102.pdf
Malang, R. (n.d.). No Titles. https://radarmalang.id/di-kabupatenada-4-251-tpq-dan-2-046-madin/

Permani, R. (2011). The presence of religious organisations, religious attendance and earnings: Evidence from Indonesia. The Journal of Socio-Economics, 40(3), 247-258. 